Sharif University of Technology
Scientia Iranica
SCIENTIA
I RAN I C A
http://scientiairanica.sharif.edu

\title{
A procedure for setting up a 180-degree sharp bend flume including construction and examinations with hydraulic structures
}

\author{
M. Vaghefi* and M. Akbari \\ Department of Civil Engineering, Persian Gulf University, Shahid Mahini Street, Bushehr, P.O. Box: 75169-13817, Iran.
}

Received 18 August 2017; received in revised form 29 November 2017; accepted 27 January 2018

\author{
KEYWORDS \\ Multi-purpose flume; \\ Sharp bend; \\ Lateral intake; \\ Acoustic Doppler \\ velocimeter; \\ Spur dike; \\ Open channel; \\ Secondary flow \\ strength.
}

\begin{abstract}
A laboratory flume should be necessarily accessible in the hydraulics laboratory in order to investigate and model different hydraulic and hydrodynamic phenomena that govern rivers. Hence, this article provides a description of the construction and setup process of a 180-degree flume, as the first 180-degree sharp bend flume containing multiple lateral intakes, in the Hydraulics Laboratory of Persian Gulf University, Iran. In addition, employing the constructed flume, this study includes a number of case studies that have been investigated with respect to flow pattern. Such experiments utilized a Vectrino velocimeter in order to obtain the $3 \mathrm{D}$ pattern of flow velocity. In the primary stage, an experiment was conducted without any hydraulic structures installed at the bend so that flow characteristics could be analyzed in a 180-degree sharp bend. An increase in the secondary flow strength and velocity was detected because of an increase in the flow depth. Therefore, it can result in an attack on the outer wall. Consequently, a T-shaped spur dike was installed at the apex of the bend to provide protection for the outer wall against streams of high velocity. A study of the flow pattern around the protective structure was conducted under clear water conditions.
\end{abstract}

(C) 2019 Sharif University of Technology. All rights reserved.

\section{Introduction}

Designing hydraulic structures has a significant role in the process of solving some problems using theories and analytical relations. Generally, there are analytical solutions to only a limited number of problems associated with flow, whereas the existence of geometrically complex walls leads to highly complicated flow equations in many cases; consequently, the behavior of the prototype cannot be predicted by theories or

\footnotetext{
*. Corresponding author. Tel.: +98 77 31222401 E-mail addresses: vaghefi@pgu.ac.ir (M. Vaghefi); m.akbari@pgu.ac.ir (M.Akbari)
}

mathematical relations. Considering the fact that there are a lot of effective variables in many hydraulic phenomena under complex boundary conditions, developing a mathematical relation based on rules and theories governing them may be tough [1]. Therefore, in order to make such phenomena rule-governed and, also, to achieve thorough knowledge and understanding of their hydraulic behavior, hydraulic and laboratory models must be constructed and studied.

The characterization of flow properties using physical and mathematical models is regarded as primary data in many applications such as designing structures, presenting a better prediction of flow behavior, and applying safety policies [2]. Moreover, the relationship between fluvial process and form is often extremely difficult to quantify using conven- 
tional field and numerical computational techniques. Physical modeling offers a complementary technique for these methods and may be used to simulate complex processes and feedbacks in many geomorphic occurrences [3]. Hydraulic models were recognized as valuable tools for designing many hydraulic and hydrodynamic issues after World War II. Davinroy [4] conducted a study of physical sediment modeling of the Mississippi River on a micro scale. Armfield [5] designed and provided open-channel facilities for hydraulic laboratories around the world for over 40 years. The Bureau of Reclamation [6,7] assembled more than 8,000 miles of irrigation-water delivery canals and designed and constructed a large-scale physical hydraulic model of the Missouri river. Abdolahpour et al. [8] constructed a concrete armored channel with a 90degree bend in the Hydraulic Laboratory of Urmia University, considered as the largest laboratory of 90degree bend channel in Iran. Calvo Gobbetti [9] designed the filling and emptying system of the new Panama Canal locks with a comprehensive physical model and, also, with a Computational Fluid Dynamics (CFD) model. Visscher et al. [10] designed a novel setup for flow visualizations and turbulence measurements in rotating high-aspect ratio ducts. The setup enabled stereoscopic PIV-measurements over a wide range of rotation numbers. Vatankhah and Mahdavi [11] developed direct solutions to area ratio of the long-throated flumes and weirs based on the upstream Froude number. It is worth mentioning that the area ratio was explicitly expressed via an elegant equation. Meanwhile, various laboratory flumes have been constructed in Tarbiat Modares University of Iran for the experiments on flow and scour patterns in a $90-$ degree bend with different radii of curvature $(R / B=2$, 3 , and 4$)$, a 180 -degree mild bend $(R / B=4)$, and a straight flume. Ghodsian and Vaghefi [12] and colleagues (Fazli et al. [13], Safarzadeh et al. [14], Vaghefi et al. [15-17], and Dehghani et al. [18]) utilized these flumes to conduct several studies in terms of river and hydraulic engineering. However, a flume with a 180-degree central angle $(R / B=2)$ combined with different lateral intakes in straight and bend reaches has not yet been constructed.

Since the majority of rivers naturally have sharp bends, studying the 180-degree sharp bend is highly significant. In fact, the main aim and novelty of this manuscript is to present different stages of the construction process of the 180-degree sharp bend flume, distinctive from other similar types including various lateral intakes in straight and bend routes. One of the most important advantages of this study is its investigation of flow pattern around the hydraulic structures placed in the constructed bend flume; the results can be generalized to the real-world problems of actual size. The attack of problematic flows on the outer banks of the river can be deflected by installing spur dikes. To this end, locating the T-shaped spur dike in the 180-degree sharp bend and studying the flow pattern around it are the next steps of our research, as addressed below.

\section{Constructed model}

A U-shaped flume with a 180-degree central angle and a rectangular section is available for $\mathrm{MSc}$ and $\mathrm{PhD}$ students for experimental purposes in the Hydraulic Laboratory of Persian Gulf University. In this lab, various experiments concerning the study and simulation of flow and scour patterns around different structures in rivers can be carried out on the flume.

The flume is composed of 6.5-meter-long upstream and 5.1-meter-long downstream straight reaches, both of which are connected via a 180-degree bend with external and internal radii of curvature of 2.5 and 1.5 meters, respectively. According to Leschziner and Rodi [19], the bend is regarded as a sharp bend $(R / B=2<3)$. The point is that the flume is the first multi-purpose 180-degree sharp bend laboratory flume, consisting of four vertical lateral intakes and four 30-degree lateral intakes in straight and bend reaches. The walls and bed are made of glass and metal, respectively, while glass walls are supported by steel frames.

Considering its properties mentioned above, this flume can be used for conducting different experiments in a wide range of Froude numbers from sub-critical to super-critical. Real and schematic 3D views of the flume in the laboratory are represented in Figure 1(a) and (b), respectively. As observed, the designed flume consists of the following parts: the main structure of the flume, water reservoir tanks, inlet reservoir, butterfly gate, outlet reservoir, lateral intakes, and flow meter and pump system, as shown in Figure 1.

The construction process of the flume is explained in detail as follows. Accordingly, since a multi-purpose flume is assumed to be capable of simulating various hydraulic phenomena, there are a variety of analyses in the field of river and hydraulic engineering carried out on it, some of which are referred to in the study.

\section{Stages of construction and installation of the flume}

First, the construction of steel and glass laboratory flumes requires the structure of the model to be placed upon a platform by using steel profiles; then, it has to be installed inside the structure of the model in the case of the glass flume. Various parts of the 180-degree sharp bend flume are constructed in collaboration with Adak Tajhiz Iranian Company and, then, transported to the Hydraulic Laboratory to be assembled and 


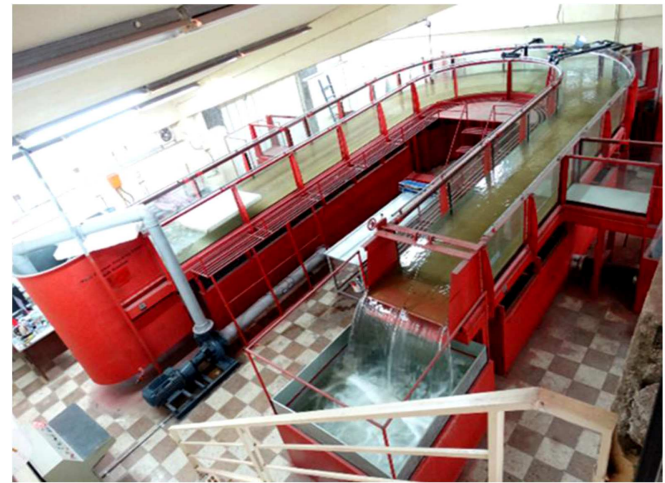

(a)

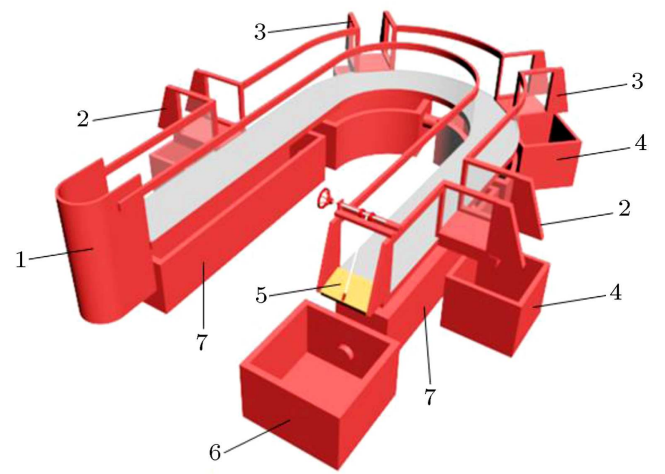

(b)

1. Inlet reservoir,

$2 \& 3$. Lateral intakes in straight and bend reaches respectively,

6. Outlet reservoir,

7. Water reservoir tanks.

4. Lateral intakes' reservoir,

5. Butterfly gate,

Figure 1. (a) Real and (b) schematic 3D views of the 180-degree sharp bend laboratory flume in the hydraulic laboratory of Persian Gulf University in Iran.

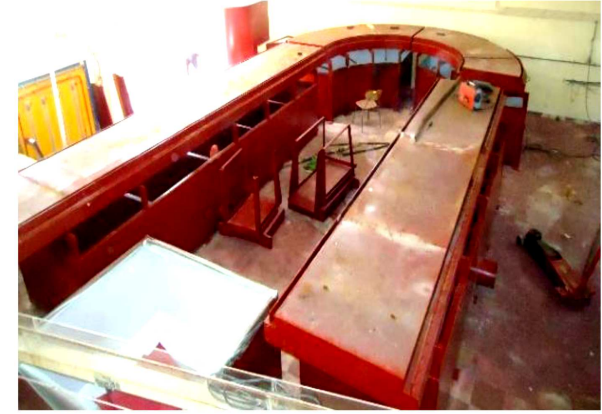

(a)

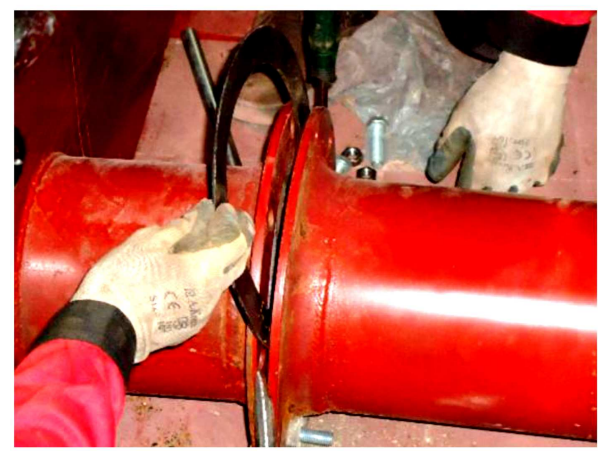

(c)

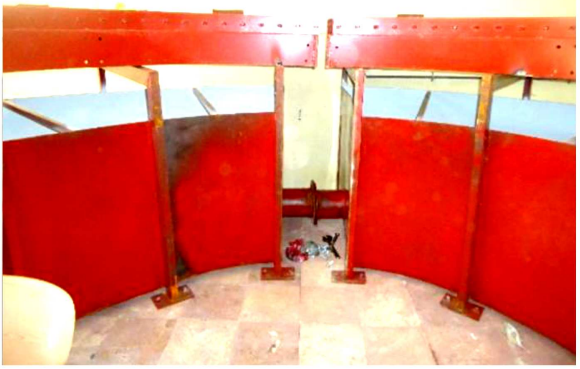

(b)

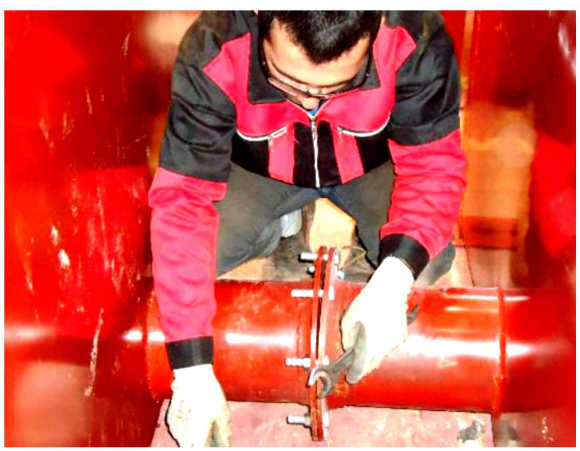

(d)

Figure 2. (a) How flume reservoirs are placed and (b) connected to each other with (c) waterproof rubber ring gasket and (d) bolts and nuts.

installed. Different steps taken to construct and install the flume are presented below.

\subsection{Placing the reservoirs and connecting them to each other}

After painting various parts of the flume reservoirs in accordance with the design, according to Figure 2(a) and (b), water reservoir tanks have been located under the main structure of the flume. These reservoirs are all ST37. As evident in Figure 2(c) and (d), waterproof rubber ring gasket, bolts, and nuts are applied to connect the reservoirs. When the reservoirs are connected to each other, the components of the bed of the main structure need to be attached to each other in both straight and bend reaches.

\subsection{Connection of the inlet reservoir to the flume bed}

Figure 3 shows an inlet reservoir (with dimensions of $1.5 \times 1.5 \times 2 \mathrm{~m}^{3}$ ) placed at the entrance of the 


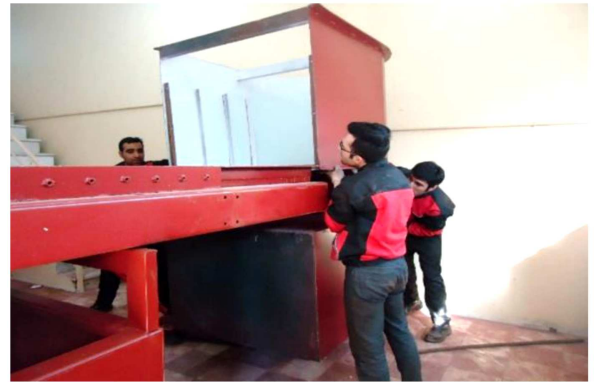

(a)

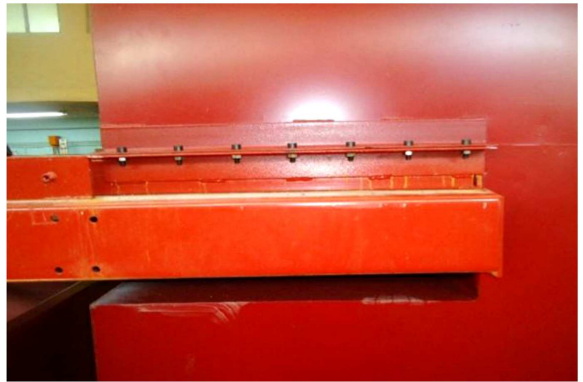

(b)

Figure 3. (a) Installation and (b) connection of the inlet reservoir to the flume bed.

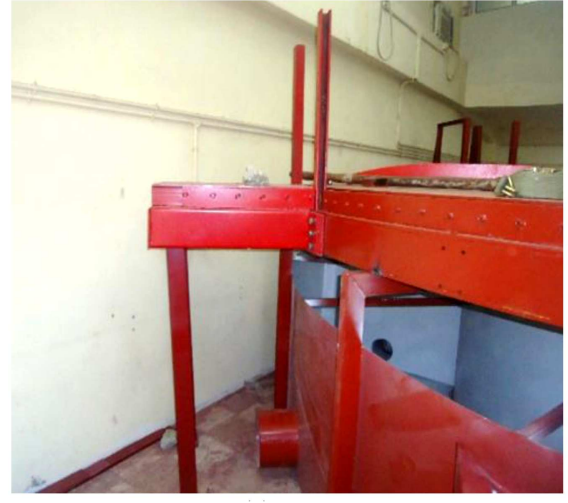

(a)

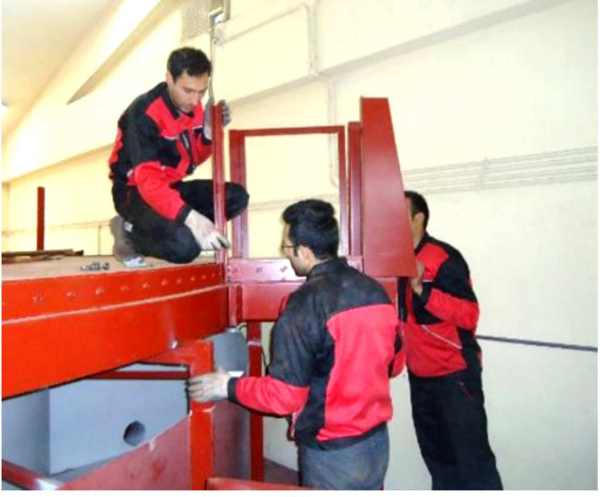

(b)

Figure 4. Attachment of (a) bed and (b) walls of the lateral intakes.

upstream straight reach, allowing for laminar flow (Figure 3(a)). Of note, both sides of the inlet reservoir are connected to the flume bed by means of Bolts and nuts (Figure 3(b)).

\subsection{Installation of lateral intakes}

The bed of the intakes is connected to the flume bed by means of bolts and nuts (Figure 4) and must be fixed perpendicularly using a leg as a support (Figure 4(a)). On the other hand, the structure of the lateral intakes is connected to the bed, as shown in Figure 4(b). Rubber washers are used on the edge of the walls of the lateral intakes for the sake of protecting the glass and preventing leaks.

\subsection{Installation of vertical frames and flume glass}

As illustrated in Figure 5, before glass installation, the glass is secured by using attached steel frames. The frames that hold the glass are installed at the outer wall of the flume on two sides, whereas a set square is used to maintain the frames perpendicular to each other. By installing the glass, these frames are connected to the upper edge of the flume. The next step is using a safety glass of $10 \mathrm{~mm}$ thick in this flume. In addition, to provide safety, inside and outside of the channel should be waterproofed; in addition, the joint between the bed and glass is sealed by a waterproof rubber

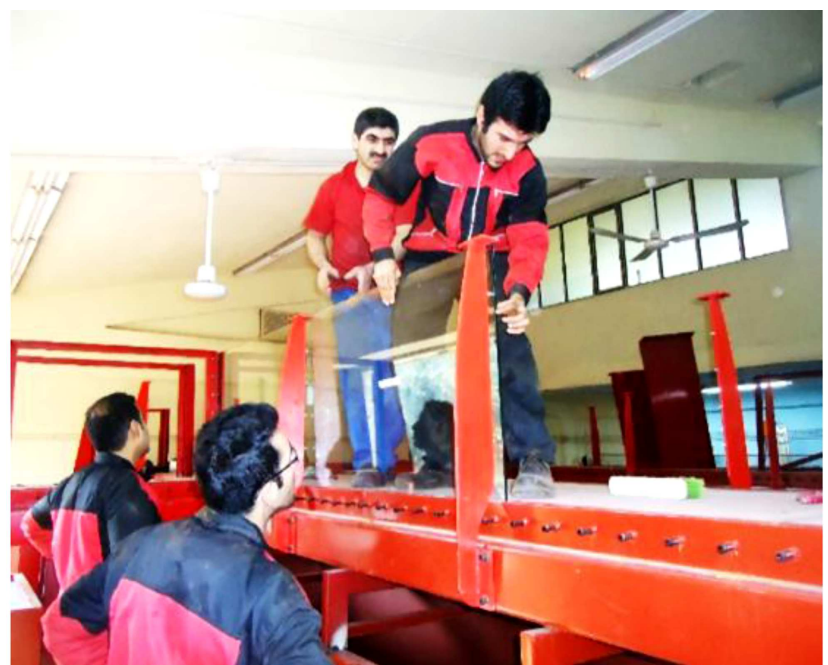

Figure 5. Installation of the safety glass with the thickness of $10 \mathrm{~mm}$.

washer, although a set square is employed to ensure right angles.

\subsection{Construction and installation of the butterfly gate}

By locating the butterfly gate at the end of the downstream straight reach and before the outlet reservoir, the flow depth is adjusted or stabilized (Figure 6). 


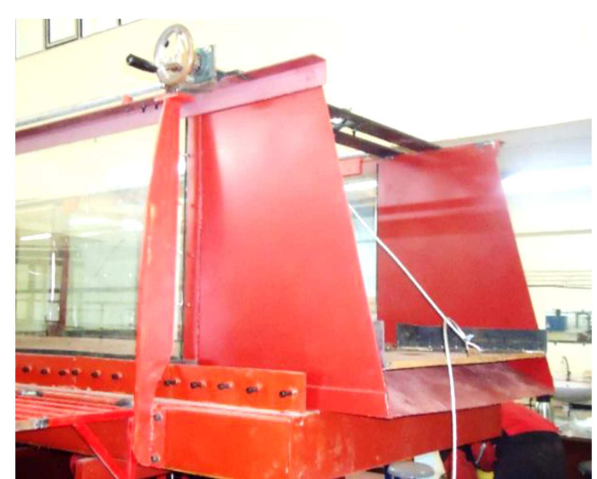

(a)

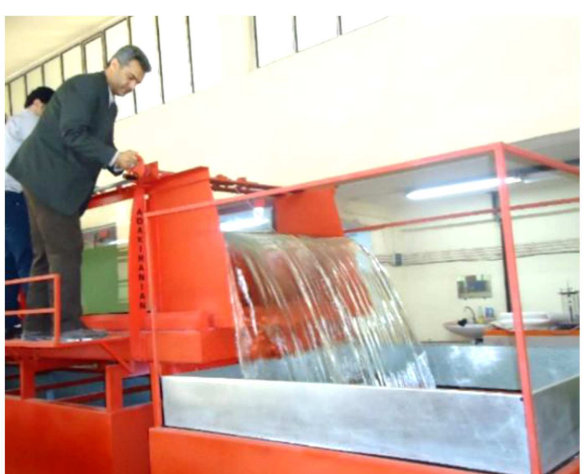

(b)

Figure 6. (a) Installation and (b) the function of the butterfly gate at the end of the downstream straight reach.

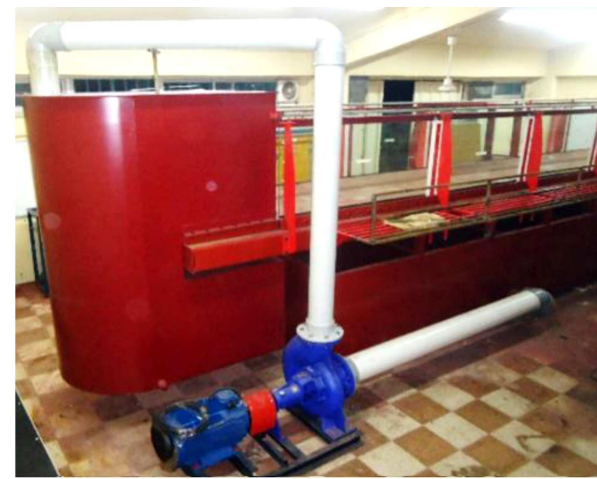

(a)

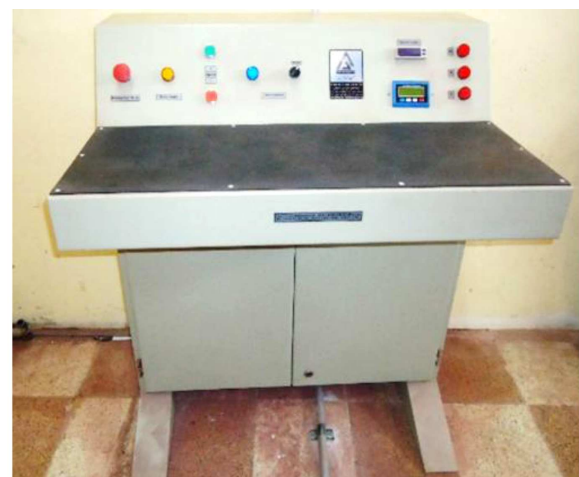

(b)

Figure 7. A view of (a) the pump system and (b) flow meter.

In other words, there is an adjuster on the gate to which the flow depth can be accustomed (Figure 6(a)). Figure 6(b) demonstrates that the flow is directed toward the outlet reservoir through the gate.

\subsection{Installation of the flow meter and pump system}

The water is pumped from the reservoirs below the flume and toward the inlet reservoir with the maximum discharge capacity of $100 \mathrm{lit} / \mathrm{s}$ by a centrifugal pump (see Figure 7; Pumpiran, type: volute casing, Iran [20]), and the joint between the pump and pipes is waterproofed (Figure 7(a)). Moreover, there is an ultrasonic flow meter with the accuracy of $\pm 1 \mathrm{~mm} / \mathrm{s}$ (Aktek, type: TFM3100-F1, Turkey [20]) to enable us to determine the desired discharge capacity of the incoming flow (Figure $7(\mathrm{~b})$ ). The reservoirs underneath the flume can hold up to $20 \mathrm{~m}^{3}$ of water to supply the required water.

\subsection{Connection of intakes' reservoirs to the main reservoir}

The lateral intakes are impounded individually and, then, the reservoirs are connected to the major reservoir located below the flume by using a rubber hose (Figure 1(b)).

\subsection{Reducing turbulence at the beginning of the inlet reservoir}

A system composed of bricks and meshing is used in order to reduce turbulence at the entrance of the flume, whereby two rows of bricks are placed between the mesh walls at the entrance of the straight reach to provide a steady flow, as shown in Figure 8.

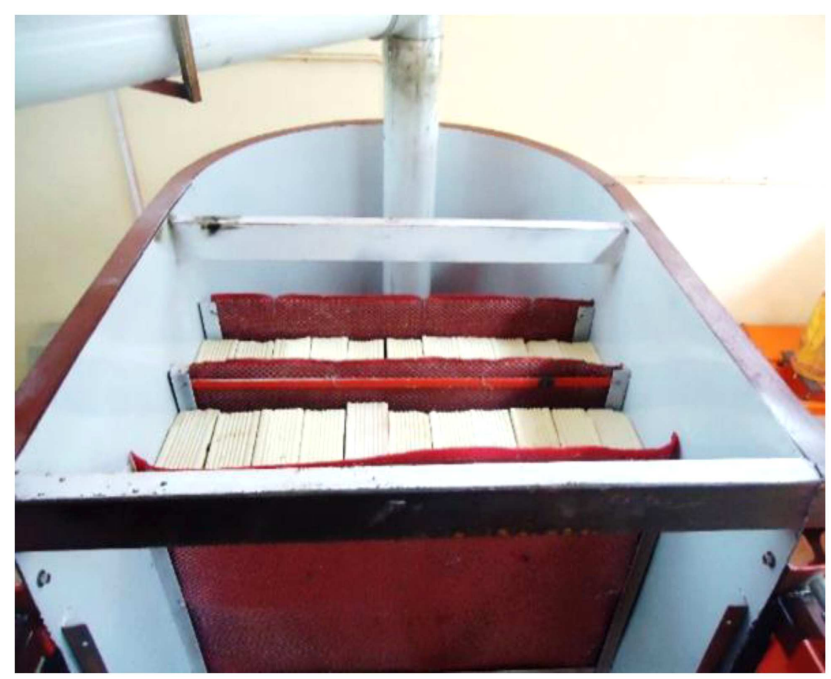

Figure 8. Reducing turbulence at the entrance of the inlet reservoir by a system of brick and meshing. 


\subsection{Flattening the flume bed}

The last step taken to construct and install the flume is to flatten out the bed of the flume to facilitate the experimental study of flow and scour patterns. Depending on the purpose of the experiment, to provide appropriate roughness for the bed, the thickness and diameter of the materials differ. Figure 9 depicts views of a rigid bed with and without the material at the bed (Figure 9(a) and (b)). Figure 9(c) also presents the mobile bed of the channel that has been designed and built in order to determine the maximum scour depth.

\section{Some applications of the provided flume}

As mentioned, this flume is considered as the first multi-purpose 180-degree sharp bend flume in Iran and used in conducting different experiments on flow and scour patterns around various structures found in rivers such as spur dikes, bridge piers, abutments, collars, submerged vanes, etc. Moreover, it is used for investigations carried out by the MSc and $\mathrm{PhD}$ students of Persian Gulf University. Currently, the MSc students majoring in hydraulic structures are working on their theses involved in the investigation of flow pattern in a 180-degree sharp bend, flow pattern around various spur dikes (T-shape, L-shape, straight spur dikes) (Figure 10), and flow and scour patterns around bridge piers (convergent and divergent piers in the same direction as the flow and perpendicular to it) using this laboratory flume (Figure 11). As displayed in Figure 10(a) and (b), there are L-shaped and Tshaped spur dikes of different sizes and lengths. In

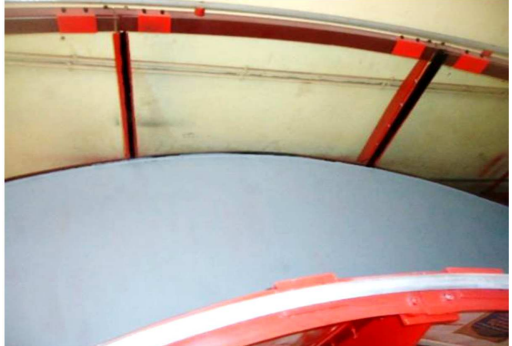

(a)

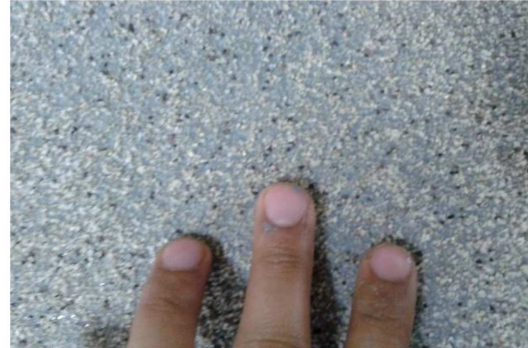

(b)

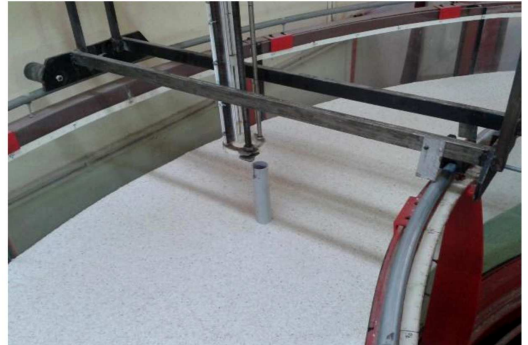

(c)

Figure 9. (a) Rigid bed without material, (b) rigid bed with material, and (c) mobile bed with the device for measuring the maximum scour depth.

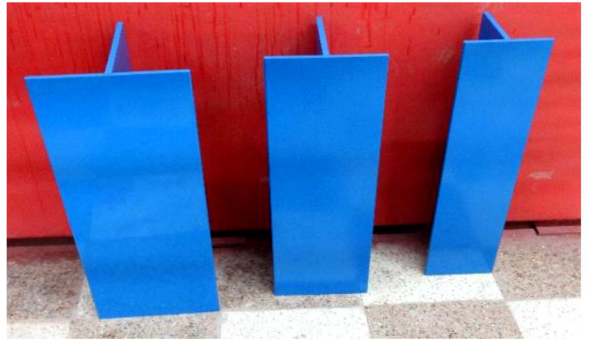

(a)

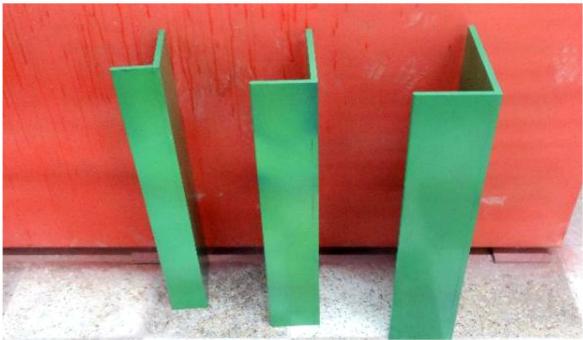

(b)

Figure 10. Samples of (a) T-shaped and (b) L-shaped spur dikes of different sizes.

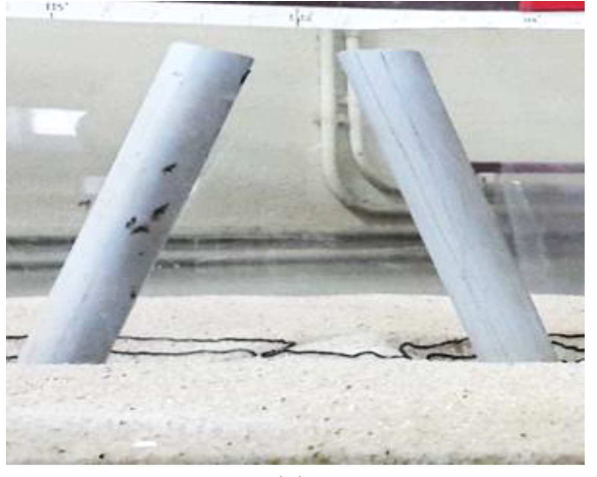

(a)

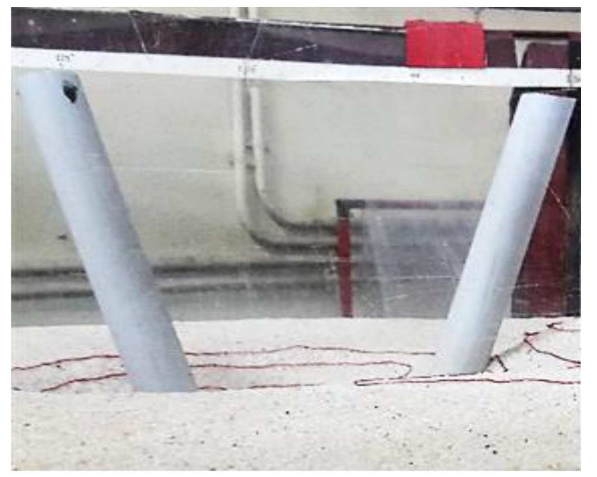

(b)

Figure 11. An example of how the piers are placed in (a) convergent and (b) divergent cases at the layer parallel to the flow. 
Figure 11(a) and (b), piers are relocated and resized in various numbers in convergent and divergent cases.

In the following, the conditions of the laboratory will be addressed where the experiments of the effect of the T-shaped spur dike length on the flow 3D velocity components' variations in a 180-degree sharp bend have been conducted.

\section{Experimental setup for flow pattern experiments around T-shaped spur dike}

The bend flume (without lateral intakes) is set up to conduct the experiments on the flow in a 180-degree sharp bend. The flume bed is assumed rigid and covered with uniform sediment characterized by the average diameter of $1 \mathrm{~mm}$. The pump is designed with a discharge capacity of $95 \mathrm{lit} / \mathrm{s}$ that remains unchanged during the experiment. The flow depth equals to $20 \mathrm{~cm}$ at the entrance of the bend. The Froude and Reynolds numbers are 0.34 and 67857 , respectively.

As observed in Figure 12, 3D velocity components of the flow in different locations are recorded using Vectrino velocimeter (Vectrino 2013, Nortek, Norway), which are then analyzed and averaged by using related software (Vectrino, Version 1.21.01; Explorer V, Version 1.57 Pro). Vectrino velocimeter, as one of the most advanced ADVs (acoustic Doppler velocimeter [21-23]), is utilized to measure velocity components and determine the 3D flow pattern. Different probes of this device are provided in Figure 12. The sidelooking probe is used to measure the flow velocity near the walls of the flume and the water surface, while the down-looking probe is used in other locations. Of note, the velocity obtained is in the range of \pm 0.01 to $\pm 7 \mathrm{~m} / \mathrm{s}$ and adjustable with $\pm 5 \%$ measured accuracy $( \pm 1 \mathrm{~mm} / \mathrm{s})$ [24-26]. During the experiments, it has always been considered to keep the values of "coloration" and "signal-to-noise ratio" above their standard values
(70\% and 20, respectively) in order to increase the accuracy of the velocimeter's measurements. The velocimeter was set at $25 \mathrm{~Hz}$ frequency [27] and, on each point, by the defined meshing, took just 120 seconds to record data.

The spur dikes used in these experiments are of T-shaped Plexiglas spur dike type. The lengths of wing $(L)$ and web $(l)$ are the same and equal to 15, 20, $25 \mathrm{~cm}$, and share the height of $25 \mathrm{~cm}$. The spur dikes are vertical and in the non-submerged condition at a 90-degree position and located in the external bend. Figure 12 depicts the location of the modeled Plexiglas spur dike in the laboratory.

\section{Investigation of flow pattern in a 180-degree sharp bend without hydraulic structures}

The flow in bends is non-uniform, and the hydraulics of mobile boundary bends are very complex due to scour and deposition in different parts of the bends. Erosion at a bend in a meandering channel is a common problem since the momentum of the flowing water changes through the rout. Every year, a lot of money is spent on protecting the bank from erosion for security purposes in the case of structures such as bridges, roads, buildings, monuments, etc. Protective strategies, such as locating spur dikes for preventing erosion, facilitate a better understanding of flow structures [28].

Some factors such as mean and turbulent flow patterns in the bend were analyzed in order to provide a better understanding of the flow pattern along bend routes with hydraulic structures (like spur dikes). In fact, a large number of studies have long been conducted on flow pattern in bends, and they have been mostly carried out on a mild, instead of a sharp, bend [19,25,26,29-39]. Of note, these studies have focused on the parameters that affect variations in scour and flow patterns along the river bends. Among these studies,

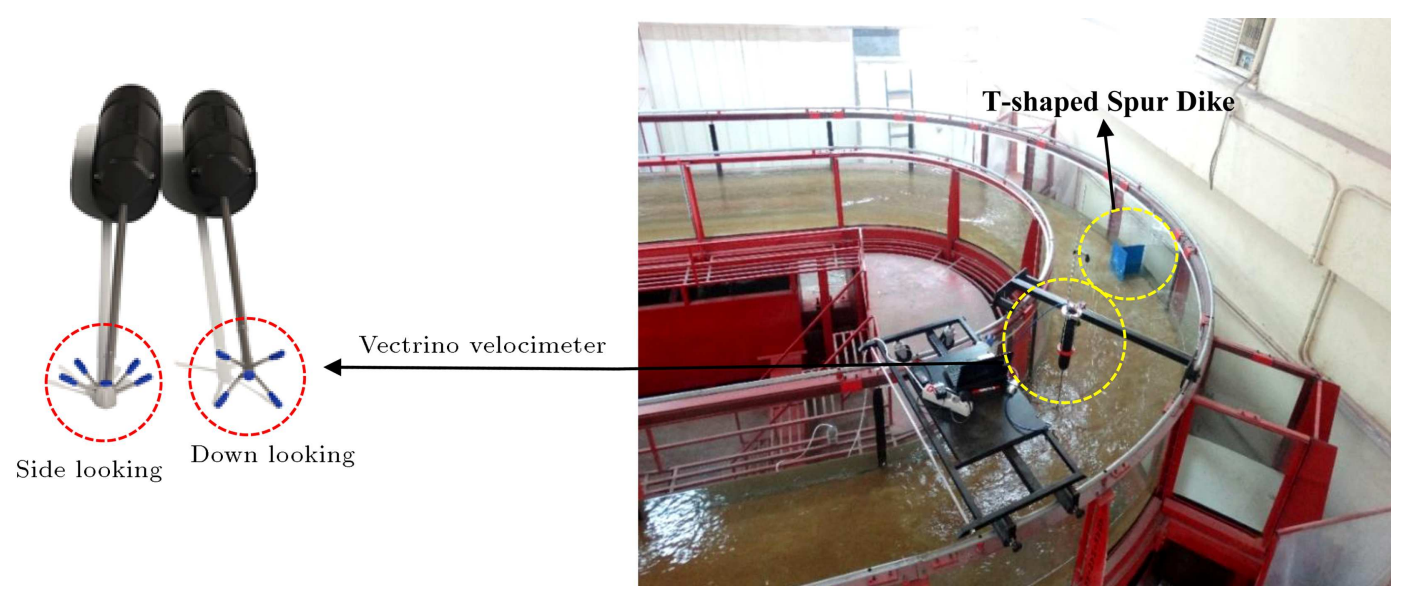

Figure 12. The view of the bend, the location of the T-shaped spur dike, the position of Vectrino velocimeter, and its probes on the bend. 


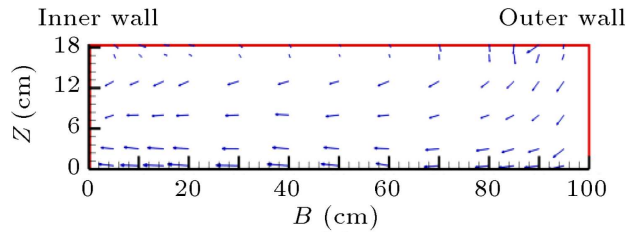

(a)

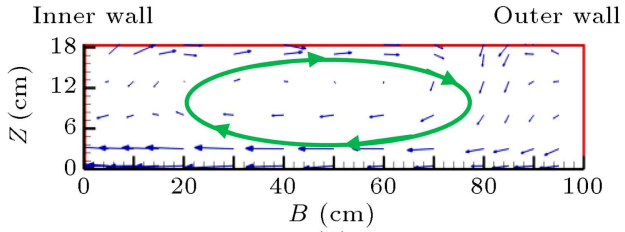

(b)

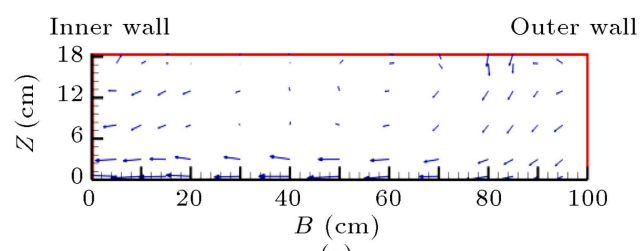

(c)

Figure 13. Flow velocity vectors through the 180-degree sharp bend at (a) 10-, (b) 90-, and (c) 170-degree cross-sections.

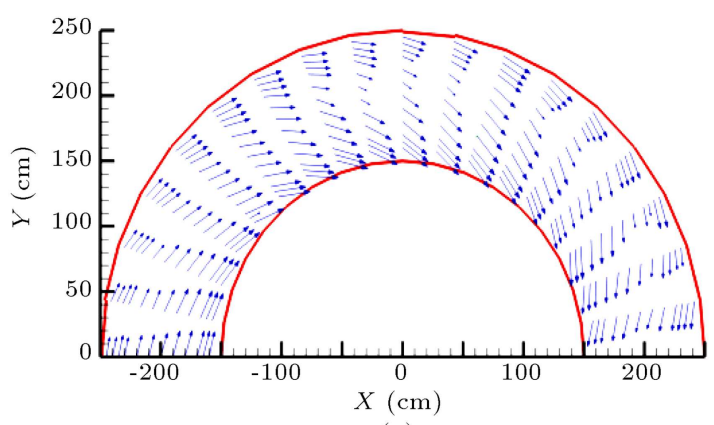

(a)

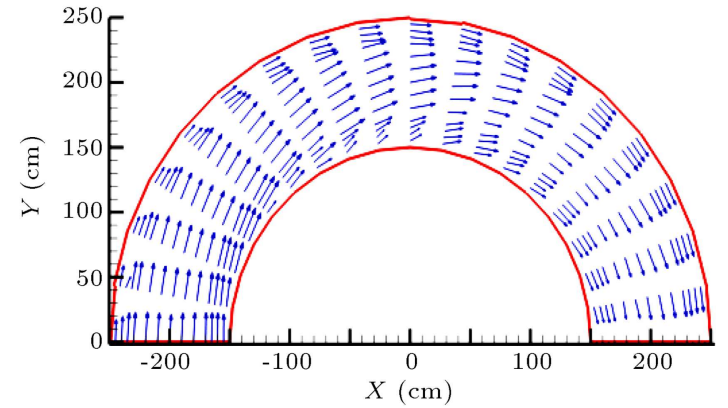

(b)

Figure 14. Flow velocity vectors along the 180-degree sharp bend at distances of (a) $5 \%$ and (b) $95 \%$ of the flow depth from the bed.

only Vaghefi et al. conducted an experiment on a 1meter-wide sharp bend with $R / B=2[25,26,39]$. The results indicated that increasing the flow depth would lead to an increase in the flow velocity so that a $40 \%$ increase approximately in the longitudinal velocity of the flow was obtained at the bend inlet in a 180degree sharp bend. Another noteworthy point is that at the layers near the bed, the streamlines have a tendency towards the inner wall of the channel, while, at the upper layer, the flow attack mostly affects the outer wall of the channel (especially from the second half of the bend onward). Hence, it is explored that an increase in the secondary flow strength is associated with an increase in the flow depth. Since the pressure gradients at the lower layers in a sharp bend dominate the secondary flows, the maximum flow velocity remains near the inner wall of the channel. Figure 13 illustrates an example of the flow velocity vectors at three different cross-sections. As observed in Figure 13(a), at first, there is a one-way flow from the outer wall towards the inner wall at the bend inlet, without any sign of an increase in the secondary flow strength or vortex formation yet, whereas, according to Figure 13(b), the vortices formed as a result of an increase in the secondary flow increase, and vorticity at the bend apex can be evidently observed (see the clockwise vortex in the middle of this section). Such an increase in the secondary flow strength continues to the end of the route. As detected at the 170-degree crosssection, it is still influenced by the strong secondary flow. Figure 14 illustrates the velocity vectors at two layers near the bed and water surface in the 180-degree sharp bend. According to this figure, at the upper layer (Figure 14(b)), the streamlines' higher tendency towards the outer wall of the channel, rather than the lower layer (Figure 14(a)), is displayed (especially, after the bend apex). This can damage and, in fact, erode the channel's outer walls if they are erodible. As mentioned earlier, the erosion may occur due to some factors such as velocity increase, the centrifugal force, and the secondary flow at the upper layer. Consequently, using a protective structure, such as a spur dike, is considered crucial in redirecting the flow velocity lines and protecting the outer wall of the bend channel.

Few experimental studies have addressed flow pattern and sediment transport around spur dikes located in a bend so far. Giri et al. [40] measured the flow properties using 3D ADV under various combinations of non-submerged spurs located in different positions to assess their effect on mean flow field in a meanderinglike laboratory flume with a smooth rigid bed. Fazli 
et al. [13] showed that increasing spur dike angle in the bend entry resulted in the expansion of dimensions of flow separation zone at the upstream of spur dike. Moreover, it was found that the scour depth increase was associated with the increasing length of spur dike by using the straight spur dike in a 90-degree bend. Vaghefi et al. [15-17] placed the T-shaped spur dike in a 90-degree mild bend and carried out several experimental studies on how some characters, such as the Froude number, the length and the position of the spur dike, the radius of curvature, etc., affected flow and scour patterns. Sharma and Mohapatra [41] conducted some experimental investigations of the flow past a spur dike on a rigid bed meandering channel with a trapezoidal cross-section. Based on the results, the length of the downstream separation zone changes corresponds to the location of the spur dike. Vaghefi et al. [42] studied the effect of the length of L-shaped spur dikes on the Reynolds shear stress variations in a 180-degree sharp bend. Consequently, it was indicated that a $67 \%$ increase in spur dike length caused an increase in bed shear stress by about $53 \%$. Mehraein and Ghodsian [43] investigated scour and flow fields around two spur dikes with different submergence ratios located in a $90^{\circ}$ developed bend. They found that the estimation of the bed shear stress using the Reynolds stresses could predict the scour initiation region correctly.

To investigate the effect of installing the spur dike in a 180-degree sharp bend and monitoring the changes of flow pattern in the bend, the T-shaped spur dike with different dimensions has been employed and, based on previous research studies, the highest decrease of scour among all shapes of spur dikes is detected. It must be pointed out that there have been no studies on the flow pattern around a T-shaped spur dike located in a 180-degree sharp bend so far. Given the importance of this study, the results of the experiment are presented as follows.

\section{The effect of lengthening the T-shaped spur dike's wing and web on the 3D flow velocity variations along the bend}

In order to investigate the important role of the $\mathrm{T}$ shaped spur dike wing and web length in flow patterns, three experiments were conducted with wing and web of the same length equal to 15,20 , and $25 \%$ of the channel width at a 90 -degree position in a clear water condition in the 180-degree sharp bend. Figure 15 presents a schematic view of the T-shaped spur dike's location in the 180-degree sharp bend in the plan. As observed, $B$ represents the channel width, $l$ is the spur dike wing length, and $L$ is the spur dike web length. Therefore, in the experiments, the spur dike wing is as long as web $(l=L)$, both of which are assumed

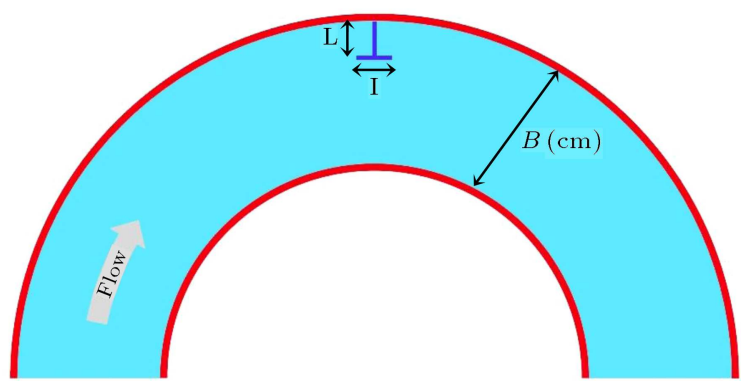

Figure 15. The schematic view of the T-shaped spur dike's position in the 180-degree sharp bend.

to be 15,20 with $25 \%$ of the channel width. The analysis results of the experiments are discussed in the following.

\subsection{The flow velocity variations in various cross-sections}

Figures 16 to 18 show the resultant flow velocity distribution at various cross-sections $(20,60,89,91$, 95 , and 150 degrees) for spur dikes with wing and web of the same length equal to 15,20 with $25 \%$ of the channel width as well as the velocity variations along the channel. In these figures, $Z$ is the flow depth, and $V_{\text {total }}$ is the resultant flow velocity. As evident in Figures 16(a), 17(a), and 18(a), the maximum flow velocity occurs near the inner bank at the 20-degree cross-section due to the presence of highly strong pressure of longitudinal gradients at the entrance of the 180-degree sharp bend. On the other hand, at the next cross-section (see Figures 16(b), 17(b), and $18(\mathrm{~b}))$, by considering the distance from the inner wall of the channel, the movement of the maximum velocity towards the inner wall is obvious. However, the velocity gets closer to the bend apex under the influence of the secondary flows by overcoming the pressure gradient present in the sharp bend [39]; in addition, more changes are generated from the presence of spur dikes of different sizes in flow velocity distribution in the bend. Moreover, as shown in Figures 16(c)-(d), 17(c)(d), and 18(c)-(d) (89- and 91-degree cross-sections at both the upstream and downstream wings of the spur dike), in the case of a short spur dike, the maximum velocity area is extended from around the inner wall to the middle of the channel, although such an area is mostly found near the inner bank for larger spurs since lengthening wing and web leads to a decrease in the area where the flow passes through. In addition, as clearly illustrated in the figures, lengthening the spur dike wing and web results in higher constriction of the section and movement of velocity towards the mid-channel. Hence, the resultant flow velocity grows. Around the spur dike, from the inner bank to the middle of the channel width, a $17 \%$ growth in the flow velocity is associated with a $67 \%$ increase in spur dike's 


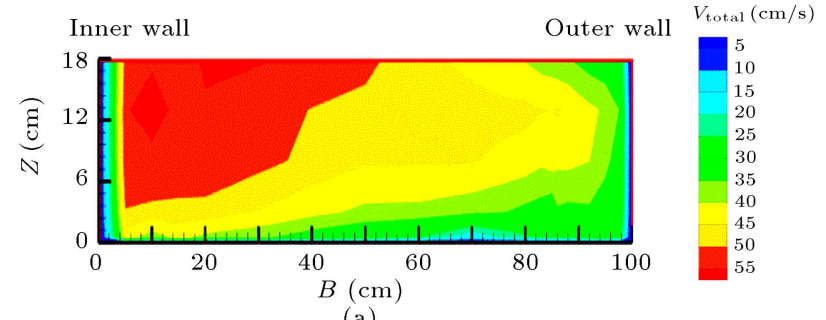

(a)

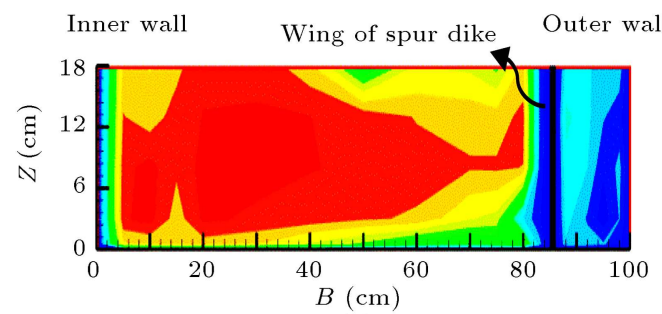

(c)

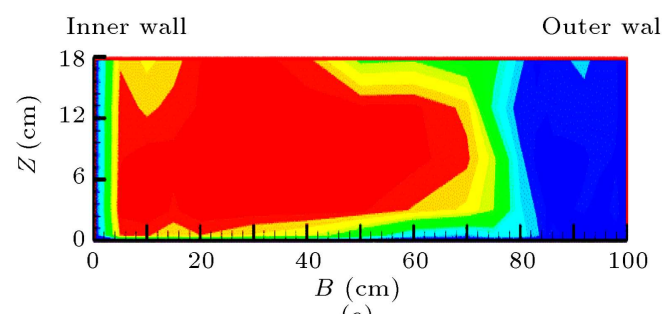

(e)

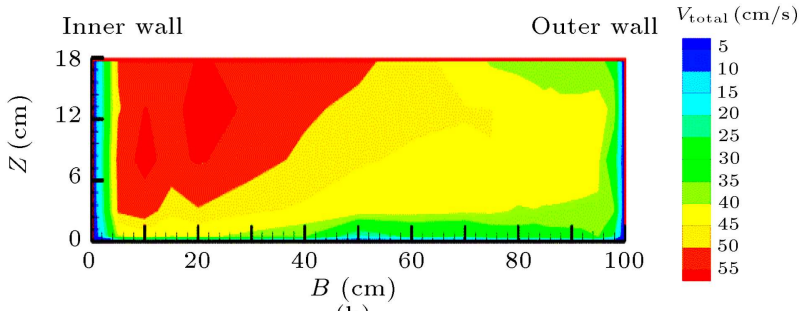

(b)

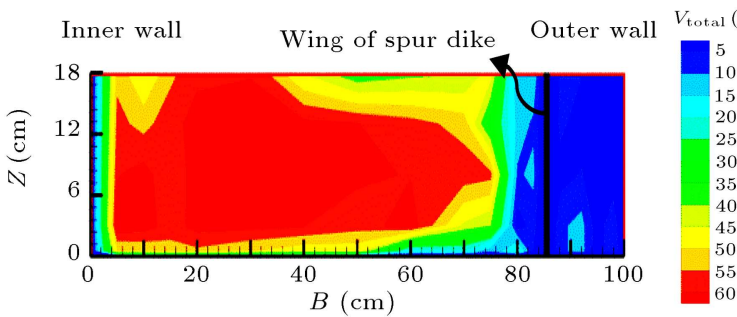

(d)

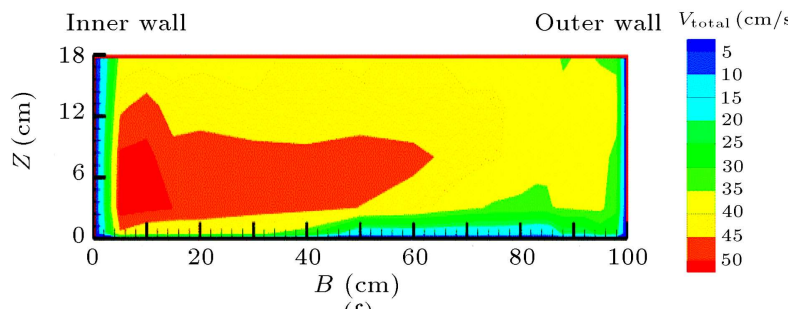

(f)

Figure 16. Samples of the velocity distribution at different cross-sections along the 180-degree sharp bend with a

T-shaped spur dike of the same wing and web length equal to $15 \%$ of the channel width at (a) 20-, (b) 60-, (c) 89-, (d) 91-, (e) 95-, and (f) 150-degree cross-sections.

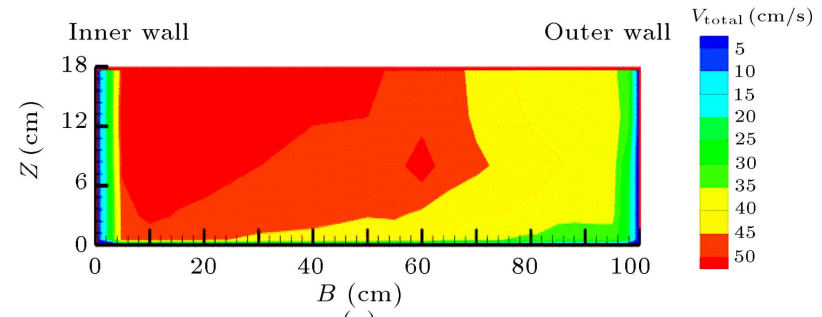

(a)

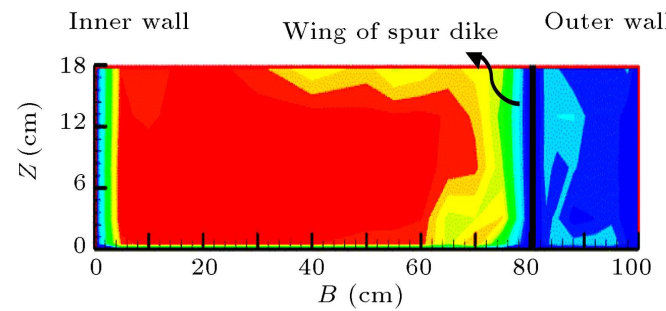

(c)

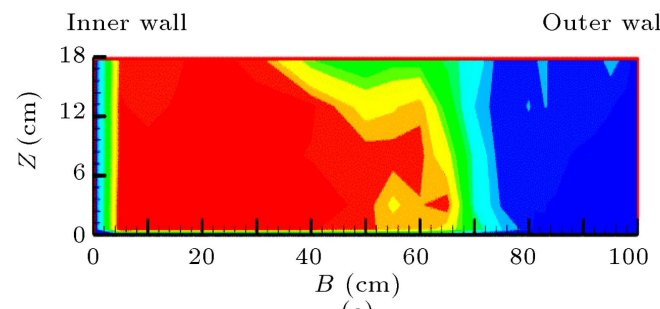

(e)
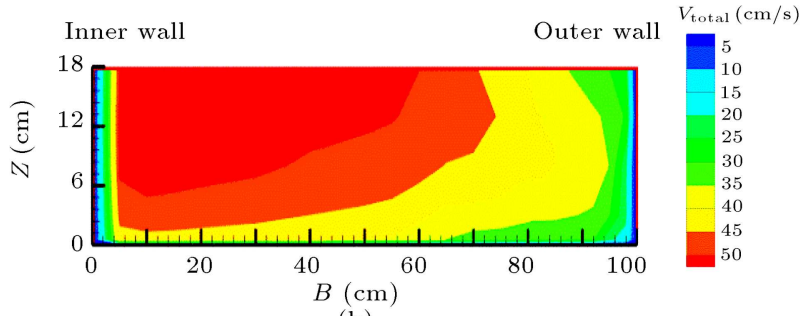

(b)

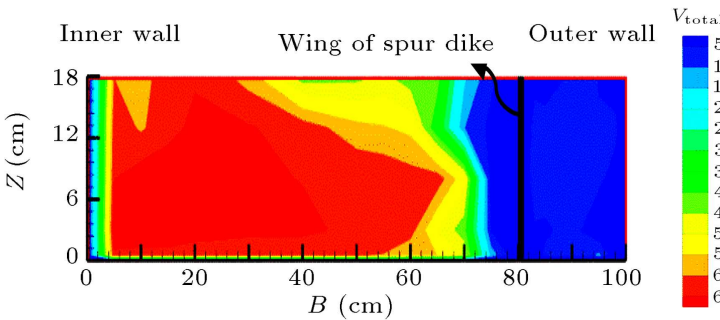

(d)

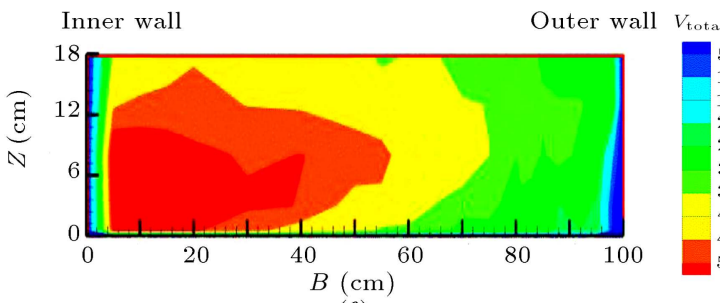

(f)

Figure 17. Samples of the velocity distribution at different cross-sections along the 180-degree sharp bend with a

T-shaped spur dike of the same wing and web length equal to $20 \%$ of the channel width at (a) 20-, (b) 60-, (c) 89-, (d) 91-, (e) 95-, and (f) 150-degree cross-sections. 


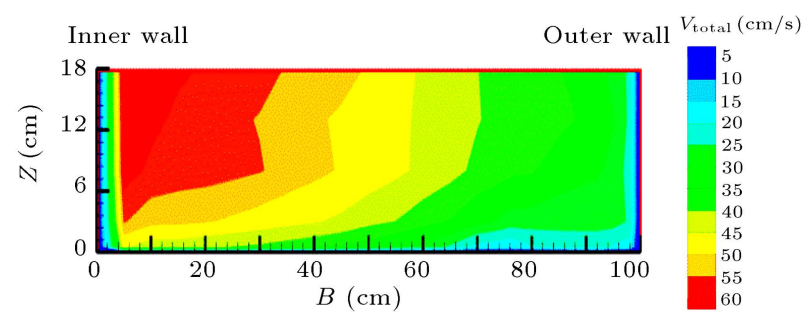

(a)

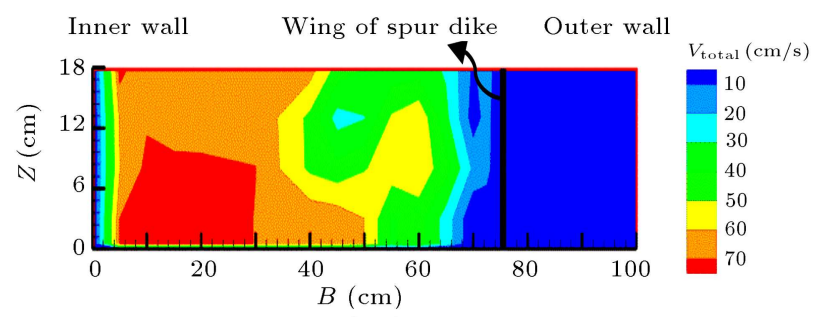

(c)

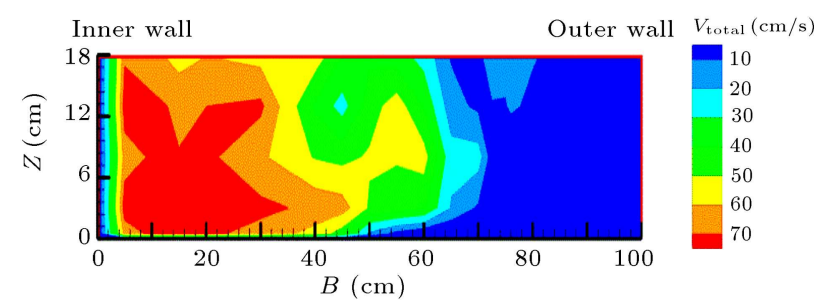

(e)

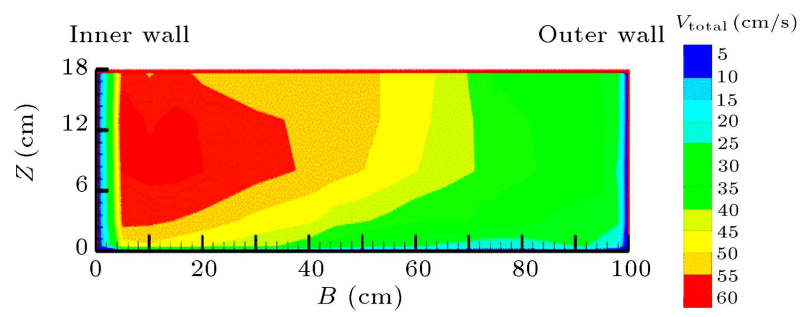

(b)

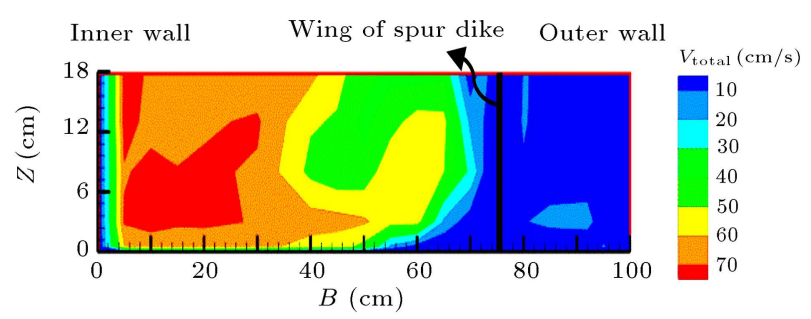

(d)

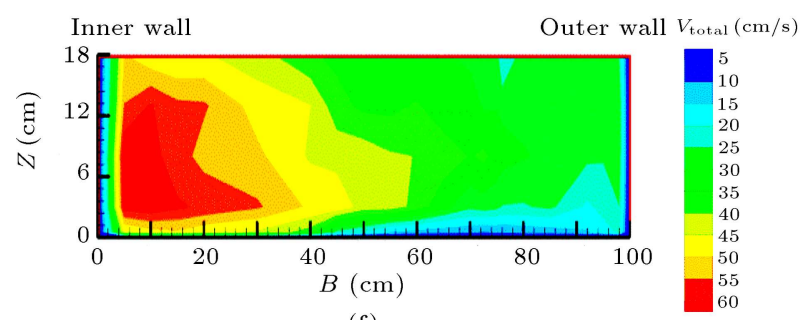

(f)

Figure 18. Samples of the velocity distribution at different cross-sections along the 180-degree sharp bend with a T-shaped spur dike of the same wing and web length equal to $25 \%$ of the channel width at (a) 20-, (b) 60-, (c) 89-, (d) 91-, (e) 95-, and (f) 150-degree cross-sections.

wing and web length (compared to the shorter spur dike).

In addition, the formation of low-velocity areas near the outer wall due to the presence of the spur dike in the external bend and the resultant return flows is evident in these figures. This is, in fact, the protective role of the T-shaped spur dikes against high-velocity flows attacking the outer wall. Moreover, since the transverse and vertical components of the flow velocity are strong in such areas, the secondary flow is expected to reach its maximum.

As a result, vortices form at such cross-sections. Therefore, the pressure gradient in these areas has lower effect on the flow pattern. It is worth mentioning that, at the 95-degree cross-section, at the downstream end of the spur dike, the outer wall of the channel is still influenced by the spur dike, while there are low-velocity areas at a distance of about $1 / 3$ of the channel width from the outer bank, too. In addition, lengthening the spur dike wing and web causes an increase in the flow velocity, whereas the maximum velocity is inclined toward the inner wall of the channel (regarding Figures 16(e), 17(e), and 18(e)).

By approaching the bend exit and studying the flow velocity contours at the 150 -degree cross-section, it is important to note that the resultant maximum flow velocity area may deviate from the inner wall after lengthening the spur dike; nevertheless, low-velocity areas can no longer be seen near the outer wall in the case of the shorter spur dike (in accordance with the previous pattern) (Figure 16(f)). Only a small area for larger spur dikes constitutes a low-velocity area (Figures 17(f) and 18(f)). This can be indicative of the effect of longer spur dikes, compared to the short one, and their higher capability to protect the outer wall of the channel even at the exit.

\subsection{The flow velocity variations in different longitudinal sections}

In order to study the flow velocity distribution under the influence of lengthening the spur wing and web length in longitudinal sections, Figures 19 to 21 depict the resultant flow velocity contours in different profiles. As is clear, in the sections near the outer wall (that is, the sections passing through the spur dikes' web and wing displayed in Figures 19(a)-(b), 20(a)-(b), and $21(\mathrm{a})-(\mathrm{b}))$, the low-velocity areas of the flow are mainly concentrated around the spur wing and web where longitudinal vortices and return flows are formed. Accordingly, it can be concluded that, for a short spur dike, at a distance of $5 \%$ of the channel width from the outer bank, the area is affected by low-velocity areas of 


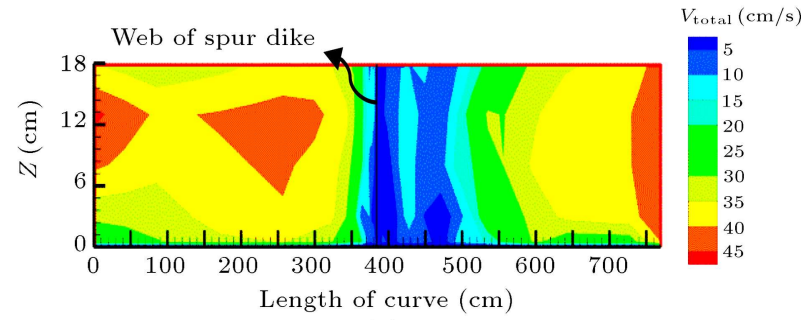

(a)

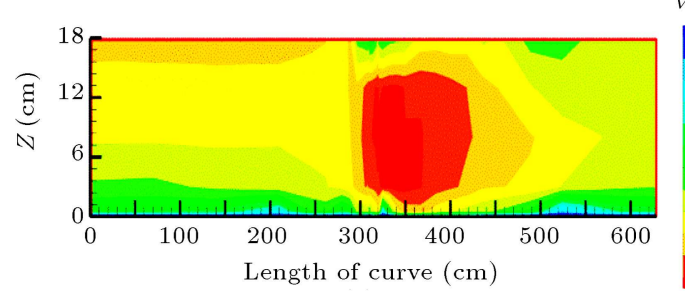

(c)

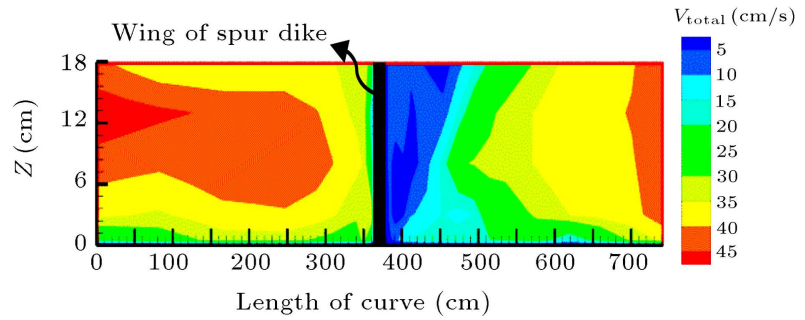

(b)

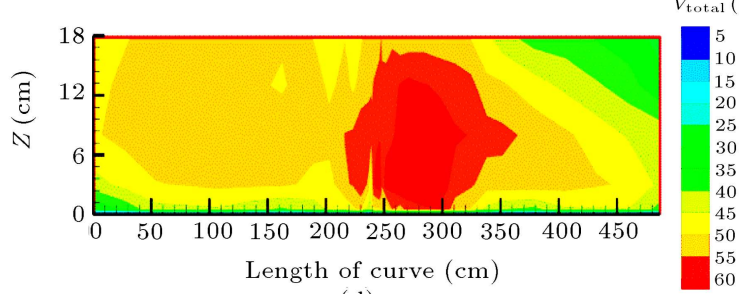

(d)

Figure 19. Samples of the resultant velocity distribution in different longitudinal sections of the 180-degree sharp bend with a T-shaped spur dike of the same wing and web length equal to $15 \%$ of the channel width in longitudinal sections at distances of (a) 5, (b) 14, (c) 50, and (d) $95 \%$ of the channel width from the outer bank.

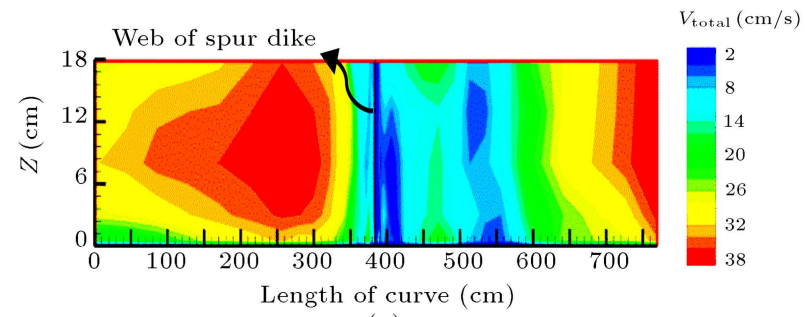

(a)

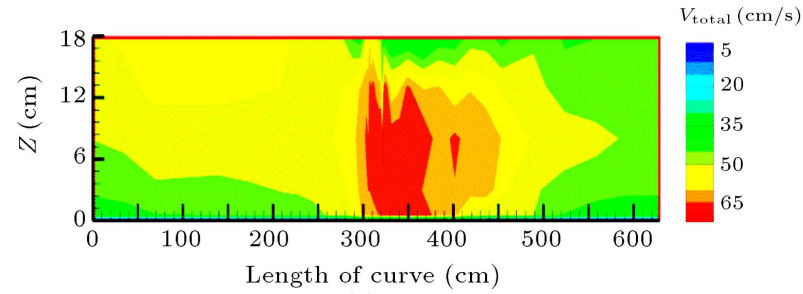

(c)

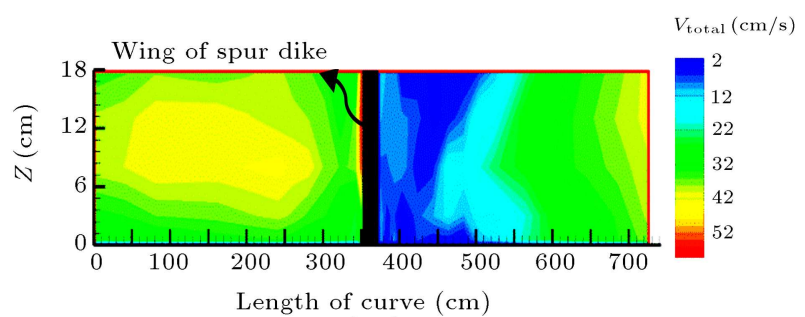

(b)

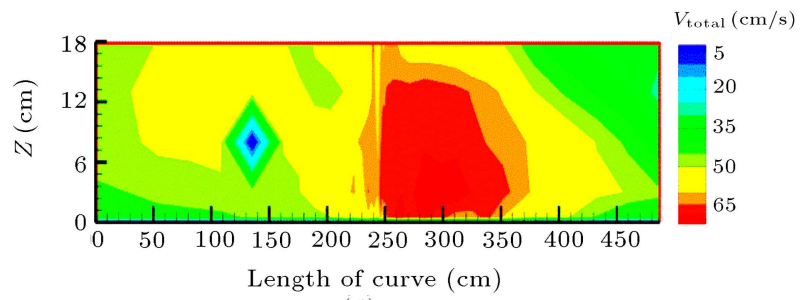

(d)

Figure 20. Samples of the resultant velocity distribution in different longitudinal sections of the 180-degree sharp bend with a T-shaped spur dike of the same wing and web length equal to $20 \%$ of the channel width in longitudinal sections at distances of (a) 5, (b) 19, (c) 50, and (d) $95 \%$ of the channel width from the outer bank.

82.5-degree to 130-degree angles, whereas lengthening the spur dike can lead to an extension in this area at downstream up to about the 150-degree angle. This is also true for the longitudinal section near the spur dike wing. In addition, high velocity is detected in areas far from the spur dike at both the beginning and the end of the bend.

Generally, in the sections around the spur dike wing and web for all the three sizes of the spur dike, the flow velocity values are classified into three categories: one low-velocity area around the wing and web as well as two high-velocity areas at both the beginning and the end of the bend.

According to Figure 20(b), for the spur dike, which is long as much as $20 \%$ of the channel width, such high-velocity areas are smaller than those of other two spur dikes. Far from the outer wall of the channel and the spur dike location in longitudinal sections at distances of 50 and $95 \%$ of the channel width from the outer bank (as in Figures 19(c)-(d), 20(c)-(d), and $21(\mathrm{c})-(\mathrm{d}))$, the maximum velocity area tends to be in the middle of the bend (at the bend apex and downstream, or at 85- to 130-degree angles), due to section constriction caused by the spur dike. It is worth mentioning that, in the presented sections, the maximum resultant velocity is obtained in the central areas of the channel near the inner wall. According to a comparison between Figures 19 to 21, lengthening 


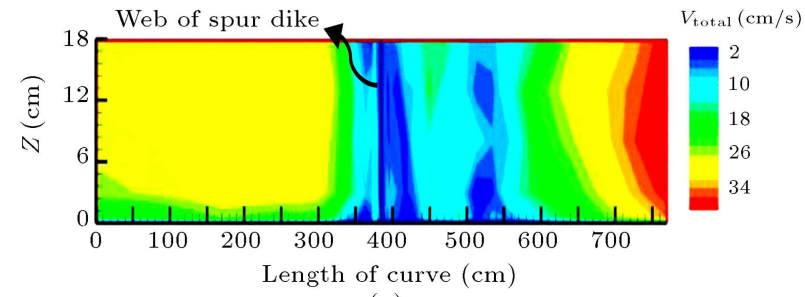

(a)

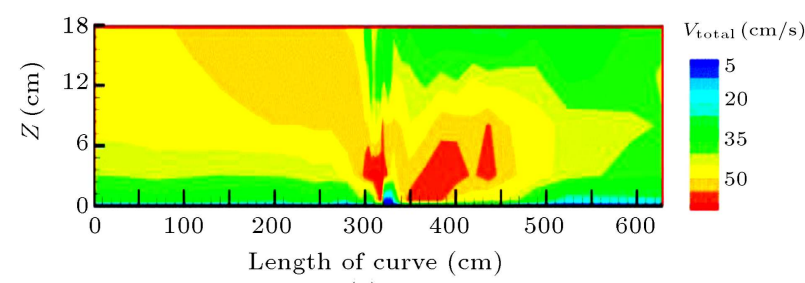

(c)

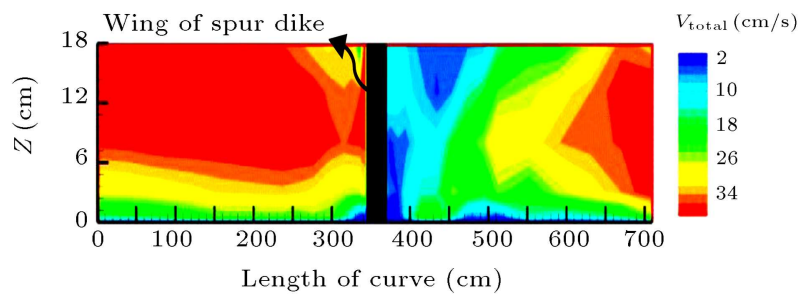

(b)

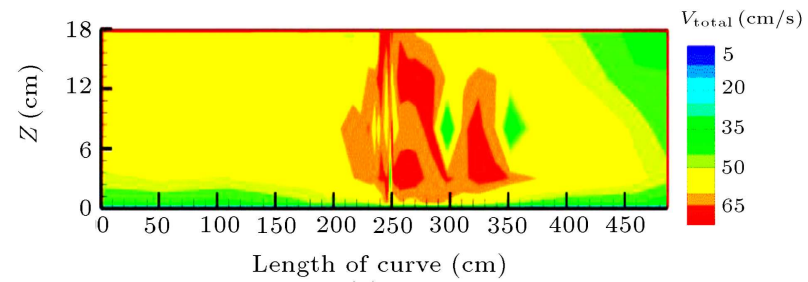

(d)

Figure 21. Samples of the resultant velocity distribution in different longitudinal sections of the 180-degree sharp bend with a T-shaped spur dike of the same wing and web length equal to $25 \%$ of the channel width in longitudinal sections at distances of (a) 5, (b) 24, (c) 50, and (d) $95 \%$ of the channel width from the outer bank.

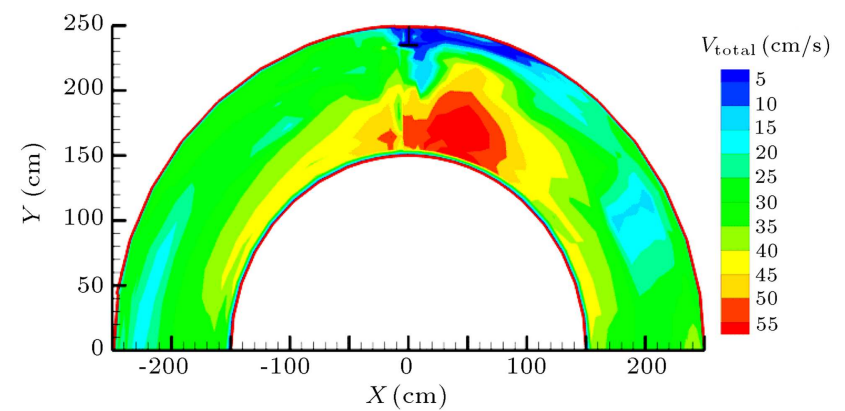

(a)

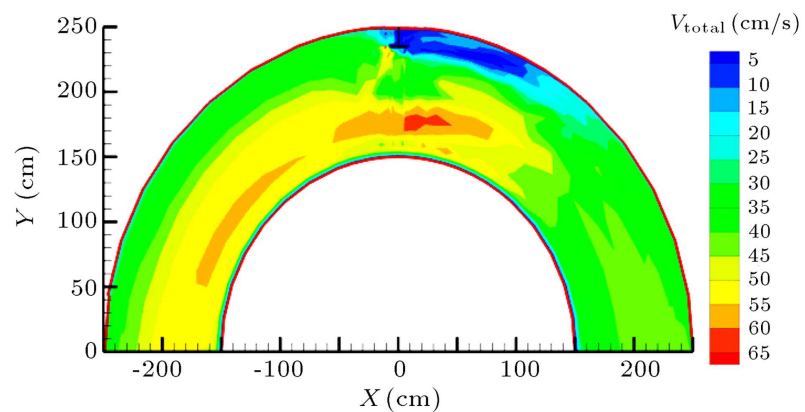

(b)

Figure 22. Samples of the resultant velocity distribution in different plans of the 180-degree sharp bend with a T-shaped spur dike of the same wing and web length equal to $15 \%$ of the channel width at distances of (a) 5 and (b) $95 \%$ of the flow depth from the bed.

the short spur dike wing and web by $67 \%$ increases the maximum velocity by $8 \%$ in the area, which is between the inner wall and the middle of the channel. On the other hand, there is an approximately $90 \%$ increase in the maximum velocity in the area that covers the outer wall (Figure 21(a)) and near the inner wall (Figure $21(d))$ for the longer spur dike.

\subsection{The flow velocity variations in different plan views}

The flow velocity contours in different plans at distances of 5 and $95 \%$ of the flow depth from the bed for different spur dikes are shown in Figures 22 to 24 . As can be observed in Figures 22(a), 23(a), and 24(a), near the channel bed, lengthening spur wing and web and, consequently, greater constriction of the section (from 15 to $25 \%$ of the channel width) increased the resultant velocity movement near the inner wall by about $27 \%$, while the near-surface velocity was estimated to be $15 \%$ greater. Concerning these figures, it is notable that at the layer adjacent to the bed (for all the spur dike sizes), the maximum velocity near the inner bank occurs in a large area of the channel width (on average, about $50 \%$ of the channel width), while an increase in depth forms a small area (on average, about $20 \%$ of the channel width) near the inner bank in order to get the layer closer to the water surface.

Moreover, a comparison of Figures 22 to 24 reveals that lengthening the spur dike may move the maximum velocity areas from the middle of the channel towards the inner bank at the layer near the bed and near water surface by $20 \%$ and $15 \%$, respectively. Besides, investigating low-velocity areas in Figure 24(a) and (b) indicates that the larger spur dike appropriately fulfills its protective role in the outer wall area; moreover, as observed, such low-velocity areas extend down to the channel's end, unlike the other two modes of the spur dike.

\section{Conclusion}

Laboratory channel facilities are undeniably essential 


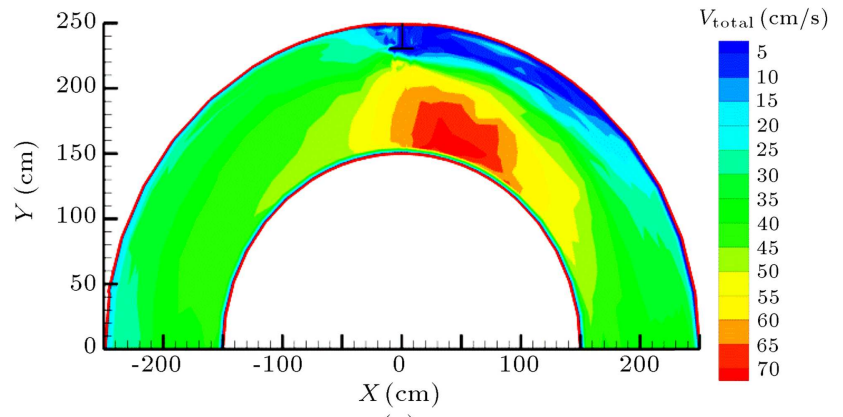

(a)

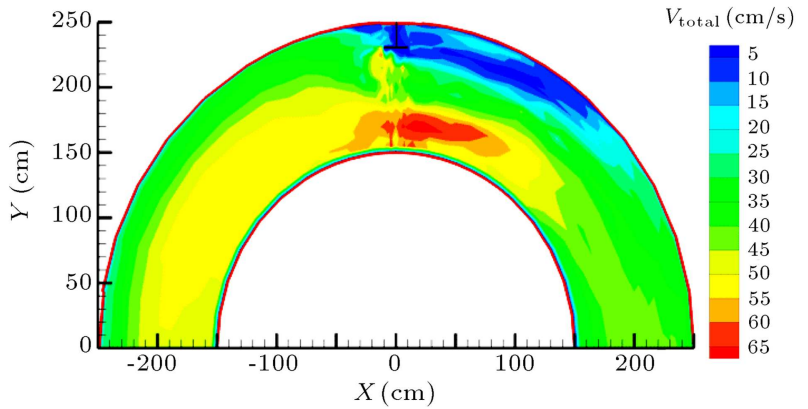

(b)

Figure 23. Samples of the resultant velocity distribution in different plans of the 180-degree sharp bend with a T-shaped spur dike of the same wing and web length equal to $20 \%$ of the channel width at distances of (a) 5 and (b) $95 \%$ of the flow depth from the bed.

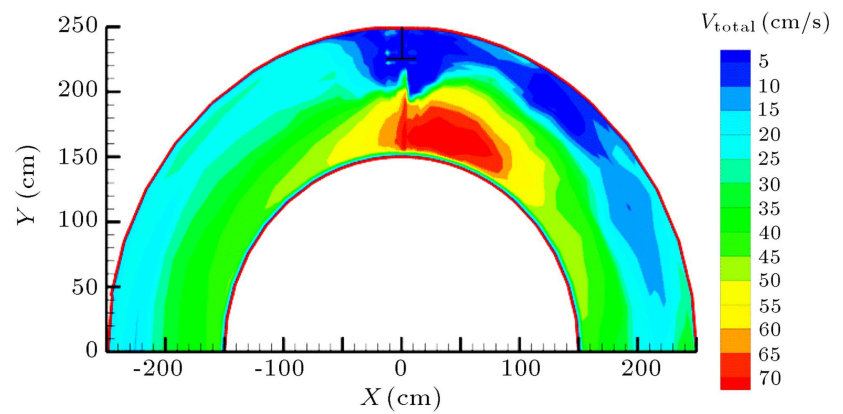

(a)

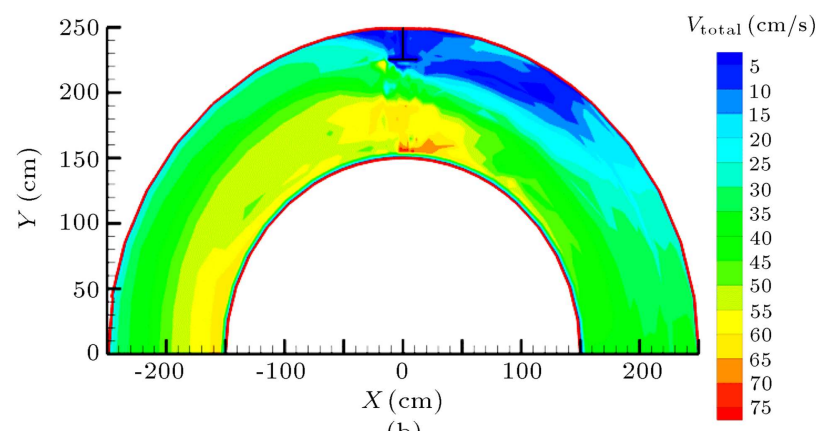

(b)

Figure 24. Samples of the resultant velocity in different plans of the 180-degree sharp bend with a T-shaped spur dike of the same wing and web length equal to $25 \%$ of the channel width at distances of (a) 5 and (b) $95 \%$ of the flow depth from the bed.

in hydraulic laboratories in order to conduct flow pattern and sediment transport experiments. Among various laboratory channels constructed in the world, multi-purpose flumes have attracted the most attention in terms of river en gineering experiments. Accordingly, this paper initially described the steps of constructing and installing the first multi-purpose 180-degree sharp bend flume in Iran. The flume consists of four lateral intakes in straight and bend routes, and its ratio of the central curvature radius to width is 2 . After constructing the channel, for the sake of investigating the flow pattern in the bend route of the channel, the state of the flow with a rigid bed was studied. The results of the experiments indicated that an increase in flow depth would increase the secondary flow strength as well as the flow velocity. As a result, the streamlines of high velocity attacked the outer wall of the channel. This can cause decay and erosion of the wall, provided that the wall is erodible. Therefore, T-shaped spur dikes, as one of the best types of spur dikes protecting the outer wall of the bend, were used to protect the outer wall of the channel. Then, variations in the $3 \mathrm{D}$ components of the flow velocity due to an increase in the spur's wing and web length were studied. The results of such experiments showed that in the spur dike area, from the inner bank to the middle of the channel's width, a $67 \%$ increase in the spur's wing and web length increased the resultant flow velocity by approximately $17 \%$ (compared to the shorter spur dike). Moreover, the short spur dike has less functionality in the protection of the channel's outer wall, while the longer spur dike extended its protective purpose down to about the bend outlet.

\section{Acknowledgements}

Research Office of Persian Gulf University has both financially and spiritually supported the construction and installation of the flume (Grant No. 101-91-245). The authors of the paper would like to extend their sincere appreciation to them and Adak Tajhiz Iranian Company for their cooperation. They would also like to appreciate Prof. Goodarz Ahmadi for his most valuable edition and partial review.

\section{References}

1. Chanson, H. The Hydraulics of Open Channel Flow, Arnold, London, England (1999).

2. Fiorot, G.H., Maciel, G.F., Cunha, E.F., and Kitano, C. "Experimental setup for measuring roll waves on 
laminar open channel flows", Flow Measurement and Instrumentation, 41, pp. 149-157 (2015).

3. Peakall, J., Ashworth, P., and Best, J. "Physical modelling in fluvial geomorphology: principles, applications and unresolved issues", In The Scientific Nature of Geomorphology, B.L. Rhoads, C.E. Thorn (Eds.) Wiley, New York, USA (1996).

4. Davinroy, R.D. "Physical sediment modeling of the Mississippi river on a micro scale", Dissertation, University of Missouri-Rolla, Missouri, USA (1994).

5. Armfield Inc. "Applied hydraulic and hydrology: Laboratory flumes and channels for hydraulic teaching and research", Engineering Teaching \& Research Equipment, Armfield Ringwood, England (2004).

6. Brent, M. and Tom, G. "Physical hydraulic model proposal for US army corps of engineers Missouri river bend model", Report, U.S. Department of the Interior Bureau of Reclamation Technical Service Center Hydraulic Investigations and Laboratory Services Group Denver, Colorado, USA (2011).

7. Wahl, T.L. and Lentz, D.J. "Physical hydraulic modeling of canal breaches", Report, U.S. Department of the Interior Bureau of Reclamation Technical Service Center Hydraulic Investigations and Laboratory Services Group Denver, Colorado, USA (2011).

8. Abdolahpour, M., Yasi, M., Behmanesh, J., and Vaghefi, M. "Construction of a concrete bend channel as a hydraulic model", Advances in Natural and Applied Sciences, 5(1), pp. 34-40 (2011).

9. Calvo Gobbetti, L.E. "Design of the filling and emptying system of the new Panama Canal locks", Journal of Applied Water Engineering and Research, 1(1), pp. 28-38 (2013).

10. Visscher, J., Andersson, H.I., Barri, M., Didelle, H., Viboud, S., Sous, D., and Sommeria, J. "A new setup for PIV measurements in rotating turbulent duct flows", Flow Measurement and Instrumentation, 22, pp. $71-80$ (2011).

11. Vatankhah, A.R. and Mahdavi, A. "Simplified procedure for design of long-throated flumes and weirs", Flow Measurement and Instrumentation, 26, pp. 79-84 (2012).

12. Ghodsian, M. and Vaghefi, M. "Experimental study on scour and flow field in a scour hole around a T-shaped spur dike in a 90 degree bend", International Journal of Sediment Research, 24(2), pp. 145-158 (2009).

13. Fazli, M., Ghodsian, M., and Saleh Neyshabouri, S.A.A. "Scour and flow field around a spur dike in a 90 degree bend", International Journal of Sediment Research, 32(1), pp. 56-68 (2008).

14. Safarzadeh, A., Salehi Neyshabouri, S.A.A., Ghodsian, M., and Zarrati, A.R. "Experimental study of head shape effects on shear stress distribution around a single groyne", Proceedings of 5th International Conference on Fluvial Hydraulics (River Flow), Braunschweig, Germany, pp. 1-10 (2010).
15. Vaghefi, M., Ghodsian, M., and Salehi Neyshabori, S.A.A. "Experimental study on the effect of a TShaped spur dike length on scour in a 90 degree channel bend", Arabian Journal of Science and Engineering, 34(2), pp. 337-348 (2009).

16. Ghodsian, M., Vaghefi, M., and Salehi Neyshabouri, S.A.A. "Experimental study on scour around a Tshaped spur dike in a channel bend", Journal of Hydraulic Engineering, 138(5), pp. 471-474 (2012).

17. Vaghefi, M., Ghodsian, M., and Adib, A. "Experimental study on the effect of Froude number on temporal variation of scour around a T-shaped spur dike in a 90 degree bend", Applied Mechanics and Materials, 147, pp. 75-79 (2012).

18. Dehghani, A.A., Azamathulla, H.M., Hashemi Najafi, S.A., and Ayyoubzadeh, S.A. "Local scouring around L-head groynes", Journal of Hydrology, 504, pp. 125131 (2013).

19. Leschziner, M.A. and Rodi, W. "Calculation of strongly curved open channel flow", Journal of the Hydraulics Division, 105, pp. 1297-1314 (1979).

20. Aktek, E.E., Ultrasonic Flow Meter User Manual TFM3100, Aktek Company, Istanbul, Turkey (2002).

21. Liao, Q., Wang, B., and Wang, P.F. "In situ measurement of sediment resuspension caused by propeller wash with an underwater particle image velocimetry and an acoustic Doppler velocimeter", Flow Measurement and Instrumentation, 41, pp. 1-9 (2015).

22. Durgesh, V., Thomson, J., Richmond, M.C., and Polagye, B.L. "Noise correction of turbulent spectra obtained from acoustic Doppler velocimeters", Flow Measurement and Instrumentation, 37, pp. 29-41 (2014).

23. Peltier, Y., Riviére, N., Proust, S., Mignot, E., Paquier, A., and Shiono, K. "Estimation of the error on the mean velocity and on the Reynolds stress due to a misoriented ADV probe in the horizontal plane: Case of experiments in a compound open-channel", Flow Measurement and Instrumentation, 34, pp. 3441 (2013).

24. Nortek, A.S., Vectrino Velocimeter User Guide, Nortek AS, Bærum, Norway (2009).

25. Vaghefi, M. Akbari, M., and Fiouz, A.R. "Experimental investigation on bed shear stress distribution in a 180 degree sharp bend by using depth-averaged method", International Journal of Scientific Engineering and Technology, 3(7), pp. 962-965 (2014).

26. Vaghefi, M. Akbari, M., and Fiouz, A.R. "Experimental investigation of the three-dimensional flow velocity components in a 180 degree sharp bend", World Applied Programming, 5(9), pp. 125-131 (2015).

27. Vaghefi, M., Mahmoodi, Q., and Akbari, M. "A Comparison among Data Mining Algorithms for Outlier Detection using Flow Pattern Experiments", Scientia Iranica, Transactions on Civil Engineering, 25(2), pp. 590-605 (2018). 
28. Barbhuiya, A.K. and Talukdar, S. "Scour and three dimensional turbulent flow fields measured by ADV at a $90^{\circ}$ horizontal forced bend in a rectangular channel", Flow Measurement and Instrumentation, 21, pp. 312321 (2010).

29. Rozovskii, I.L., Flow of Water in Bend of Open Channel, Academy of Sciences of the Ukrainian SSR, Institute of Hydrology and Hydraulic Engineering, Kiev, Ukraine (1957).

30. Ippen, A.T. and Drinker, P.A. "Boundary shear stresses in curved trapezoidal channels", Journal of the Hydraulics Division, 88, pp. 143-179 (1962).

31. Nouh, M. and Townsend, R.D. "Shear-stress distribution in stable channel bends", Journal of the Hydraulics Division, 105, pp. 1233-1245 (1979).

32. Wu, W., Rodi, W., and Wenka, T. "3D numerical modeling of flow and sediment transport in open channels", Journal of Hydraulic Engineering, 126(1), pp. $4-15$ (2000).

33. Shams, M., Ahmadi, G., and Smith, D.H. "Computational modeling of flow and sediment transport and deposition in meandering rivers", Advances in Water Resources, 25(6), pp. 689-699 (2002).

34. Blanckaert, K. and Graf, W.H. "Momentum transport in sharp open-channel bends", Journal of Hydraulic Engineering, 130(3), pp. 186-198 (2004).

35. Roca, M. Martín-Vide, J.P., and Blanckaert, K. "Reduction of bend scour by an outer bank footing: Footing design and bed topography", Journal of Hydraulic Engineering, 133(2), pp. 139-147 (2007).

36. Abhari, M.N., Ghodsian, M., Vaghefi, M., and Panahpur, N. "Experimental and numerical simulation of flow in a 90 bend", Flow Measurement and Instrumentation, 21, pp. 292-298 (2010).

37. Albayrak, I. and Lemmin, U. "Secondary currents and corresponding surface velocity patterns in a turbulent open-channel flow over a rough bed", Journal of Hydraulic Engineering, 137(11), pp. 1318-1334 (2011).

38. Uddin, M.N. and Rahman, M.M. "Flow and erosion at a bend in the braided Jamuna River", International Journal of Sediment Research, 27(4), pp. 498-509 (2012).

39. Vaghefi, M., Akbari, M., and Fiouz, A.R. "An experimental study of mean and turbulent flow in a 180 degree sharp open channel bend: Secondary flow and bed shear stress", KSCE Journal of Civil Engineering, 20(4), pp. 1582-1593 (2016).
40. Giri, S., Shimizu, Y., and Surajate, B. "Laboratory measurement and numerical simulation of flow and turbulence in a meandering-like flume with spurs", Flow Measurement and Instrumentation, 15(5), pp. 301-309 (2004).

41. Sharma, K. and Mohapatra, P.K. "Separation zone in flow past a spur dyke on rigid bed meandering channel", Journal of Hydraulic Engineering, 138(10), pp. 897-901 (2012).

42. Vaghefi, M., Akbari, M., and Adib, A. "The effect of Lshaped spur dikes on Reynolds shear stress in a bend", 10th International River Engineering Conference, Ahwaz, Iran, pp. 38-49 (2016).

43. Mehraein, M. and Ghodsian, M. "Experimental study on relation between scour and complex 3D flow field", Scientia Iranica, Transactions on Civil Engineering, 24(6), pp. 2696-2711 (2017).

\section{Biographies}

Mohammad Vaghefi is an Educational Assistant of Engineering Faculty and, also, an Associate Professor of Hydraulic Structures at Persian Gulf University, Bushehr, Iran. He received his BSc and MSc in Civil Engineering from Shiraz University (Iran) and obtained his $\mathrm{PhD}$ in hydraulic structures from Tarbiat Modares University (Iran) in 2009. His research interests include open channel hydraulics, experimental methods in hydraulic structures, river engineering, sediment transport, fluid mechanics, and hydrodynamics. He has published more than 150 articles in peer-reviewed journals and 240 papers in conference proceedings so far. He has also supervised more than $50 \mathrm{MSc}$ students.

Maryam Akbari earned her BSc and MSc degrees in Civil Engineering from Persian Gulf University in 2012 and 2015, correspondingly. She has achieved the first place in the "Best MSc Thesis" in the field of hydraulic and water engineering in Iran in 2015. Her research interests are in the areas of flow measurement, experimental modeling, river flow, open channel hydraulics, hydraulic structures, and fluid mechanics. She is the author and co-author of 16 published papers in journals and 6 presented papers at national and international conferences. 